\title{
New Approach for Hybrid Stenting of the Aortic Arch in Low Weight Children
}

\author{
Manolis Georgievich Pursanov, MD*, Andrey Andreevitch Svobodov, MD, \\ Elena Grigoryevna Levchenko, MD, Ulugbek Urazbayevitch Atajanov, MD
}

Bakoulev Scientific Center for Cardiovascular Surgery, Moscow, Russian Federation

\begin{abstract}
We present the first case of hybrid stenting of coarctation of the aorta using a retrograde approach through the descending aorta. An 8-month-old, $5.7 \mathrm{~kg}$ infant developed severe obstructive lesion of the aortic arch and isthmus after primary correction of the common arterial trunk and surgical management of coarctation of the aorta. As a result, emergency intervention was needed. Taking into the account the low body weight of the patient and the impossibility of using a transfemoral approach, we decided to obtain access through a 6th intercostal space posterolateral thoracotomy to advance a 6-F guiding catheter to the descending aorta via counter-aperture. After implantation of a Valeo stent, there were no complications, and complete elimination of the obstruction was achieved. This case demonstrates that a retrograde hybrid stenting technique via the descending thoracic aorta for aortic isthmus and arch obstruction produces good anatomical and hemodynamic results and can be applied in cases with no other alternative.

Copyright @ 2017 Science International Corp.
\end{abstract}

\section{Key Words}

Coarctation/recoarctation of the aorta $\cdot$ Hybrid stenting - Low weight children

\section{Introduction}

Recurrent obstructive lesions of the arch and isthmus of the aorta are common complications after reconstructive operations in patients with hypoplastic

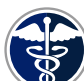

Fax +1 2037853346

E-Mail: jshd@scienceinternational.org

http://structuralheartdisease.org/

\author{
(C) 2017 Journal of Structural Heart Disease \\ Published by Science International Corp. \\ ISSN 2326-4004 \\ Accessible online at: \\ http://structuralheartdisease.org/
}

left heart syndrome, interrupted aortic arch, or hypoplasia of the aortic arch as well as patients with complex congenital heart disease $[1,2]$. The main method of treatment of aortic recoarctation in young children is percutaneous transluminal angioplasty (PTA) [3-6]. However, PTA is not effective in patients with long narrowed segments of the aortic arch, and a high incidence of restenosis occurs during the first year after the procedure $[7,8]$. A more radical method is stenting of the aortic arch and isthmus via implantation of a stent that can be expanded as the body grows [9]. However, it is not possible to perform such a percutaneous procedure in infants and young children due to their small vessels and the large delivery catheters needed for the procedure $[10,11]$. To overcome these difficulties, a hybrid technique for stent implantation via access through the ascending aorta has been introduced [9, 12]. However, implementation of this technique is possible only when sternotomy is performed.

\section{Case Presentation}

Patient O. $(2.7 \mathrm{~kg})$ was admitted to the clinic at 4 days of age in critical condition, with common arterial trunk, coarctation of the aorta, and patent ductus arteriosus. Given the state of the child, a decision was made to resolve the condition. An operation was performed through a posterior-lateral thoracotomy. Coarctation of the aorta was shown by a hypoplastic isthmus of the aorta. The contracted site was resected through a

\section{* Corresponding Author:}

Manolis Georgievich Pursanov, MD

Bakoulev Scientific Center for Cardiovascular Surgery

Rublevskoe Shosse 135, Moscow 121552, Russian Federation

Tel.: +8 49541478 89; Fax: +8 926529 3223; E-Mail: mpursanov@gmail.com 
superimposed "end-to-end" anastomosis. The pulmonary arteries were narrowed to $3 \mathrm{~mm}$ in the mouths with cuffs made of Gore-Tex material. The postoperative period was complicated by cardiac and respiratory failure, but the patient's condition stabilized by day 20 . Radical correction of the ventricular septal defect, cuff removal from the pulmonary arteries, and creation of the right ventricular outflow tract using a valve-containing xenopericardial graft No. 10 was performed under artificial blood circulation. The postoperative period was complicated by polyorganic insufficiency, but the child was discharged from the hospital in satisfactory condition 36 days after surgery.

At scheduled follow-up visits 3 and 5 months after the operation, increased pressure gradient at the aortic isthmus was noted, and the child was hospitalized for surgical correction of this complication at 8 months of age. The child had reduced nutrition with blood pressures of $140 / 80 \mathrm{mmHg}$ in the right arm, $80 / 40 \mathrm{mmHg}$ in the left arm, and $60 / 30 \mathrm{mmHg}$ in the right leg.

Electrocardiography showed right axis deviation. A chest X-ray demonstrated cardiomegaly with a car- diothoracic ratio of $67 \%$. Echocardiography revealed an enlarged left atrium and thickened left ventricular posterior wall with normal ejection fraction. The aortic valve was tricuspid with a dilated ascending aorta. There was moderate prolapse of the mitral valve with moderate regurgitation. The gradient across the long segment narrowing was $86 \mathrm{mmHg}$. The right ventricle was enlarged. No obstruction was noted across the right ventricular outflow tract or branch pulmonary arteries.

Multislice computed tomography was performed to clarify the anatomy and determine the localization of the lesion (Figure 1A and 1B). There was expansion of the ascending aorta at the level of the Valsalva sinus to $19-20 \mathrm{~mm}$ and at the level of the sinotubular junction to $17 \mathrm{~mm}$; the diameter of the ascending aorta in front of the brachiocephalic trunk was $8 \mathrm{~mm}$. Brachiocephalic vessels originated from separate ostiums; the ostium of the left common carotid artery was located immediately after the origination site of the brachiocephalic vessels, and the last trunk originating from the aortic arch was the left subclavian artery, which narrowed at the ostium. There
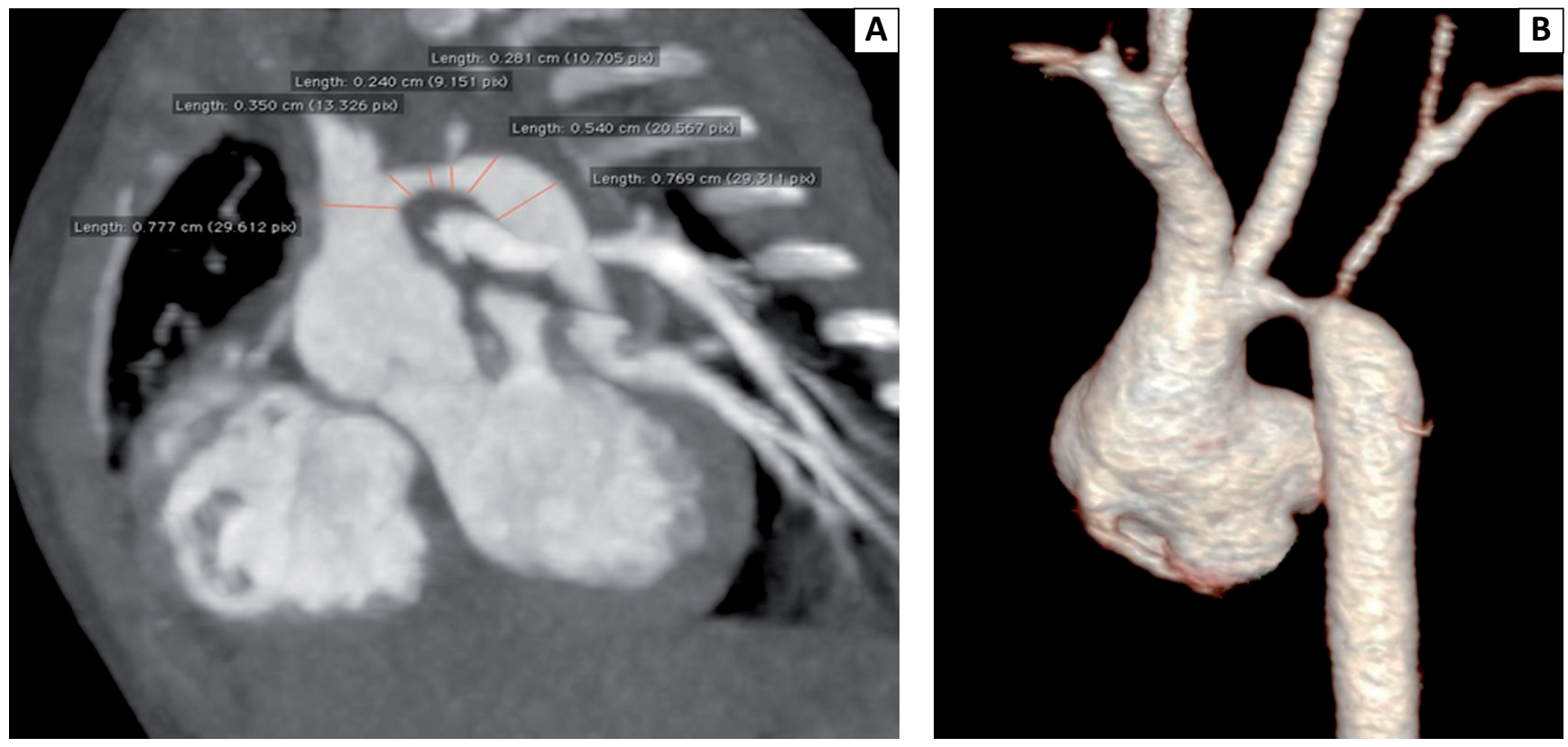

Figure 1. Multi-slice computed tomography of the heart with contrast injection. Maximum intensity projection (Panel $A)$ and threedimensional reconstruction (Panel B) showed expansion of the ascending aorta. The left common carotid artery originated near the brachiocephalic trunk. There was prolonged acute stenosis of the aortic arch from the ostium of the left common carotid artery to the aortic isthmus as well as ostial stenosis of the left subclavial artery. 
was uneven narrowing of the aortic arch between the left common carotid artery and left subclavian artery to $2.4-2.8 \mathrm{~mm}$. The isthmus of the aorta immediately after the ostium of the left subclavian artery had a diameter of $4.3 \mathrm{~mm}$. The descending thoracic aorta had a diameter of approximately $8 \mathrm{~mm}$, and the diameter of the thoracic aorta at the diaphragm level was $6.7 \mathrm{~mm}$.

Given the high risk of open surgery for reconstructing the aortic arch, a decision was made to perform endovascular intervention. However, the patient's low weight and need for implantation of a stent that could be expanded as the body grows limited the use of access through the femoral artery. Therefore, a hybrid approach was proposed.

The hybrid procedure was performed in a cardiosurgical operating room using a mobile angiocardiographic unit OEC 9900 (General Electric Healthcare, Livonia, MI, USA). The patient underwent posterolateral thoracotomy at the 6th intercostal space on the left. A descending aorta segment was isolated, on which a purse string suture was applied. Through the counter-aperture, $3 \mathrm{~cm}$ below the operation field, a 6-F Mullins delivery system (NuMed, Cornwall, ON, Canada) was transcutaneously inserted into the thoracic descending aorta (Figure 2). The delivery system was

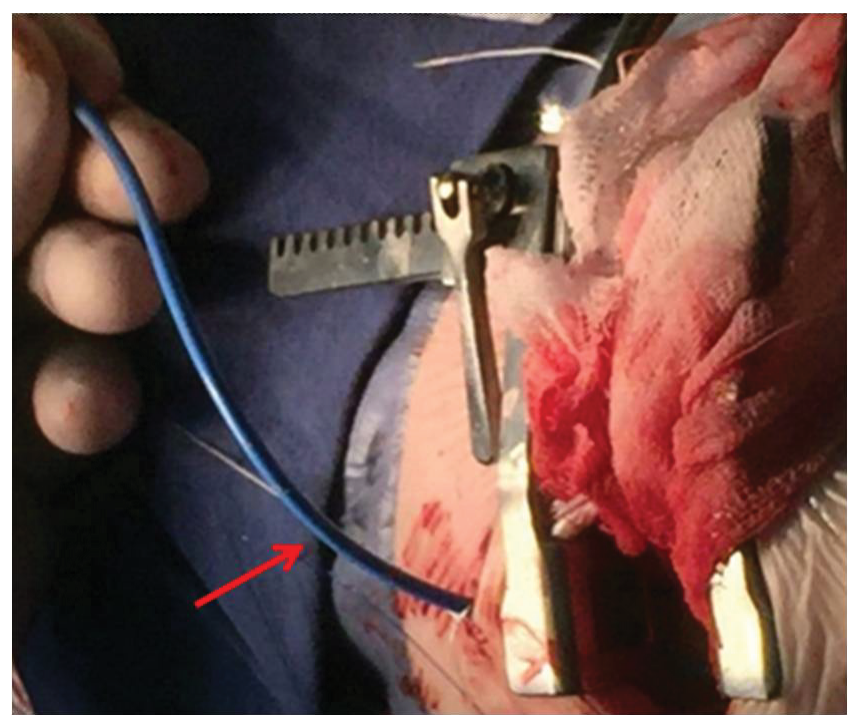

Figure 2. Access site through lateral thoracotomy in the 6th intercostal space during the hybrid stenting procedure. The delivery catheter (arrow) was advanced through the thoracic aorta through a counter-aperture $3 \mathrm{~cm}$ below the operation field. carried on the guidewire to the initial section of the descending thoracic aorta through the lateral port, at which angiography of the aortic arch was performed (Figure 3A). A prolonged narrowed segment of the arch and isthmus of the aorta with a diameter of 2.4$3.0 \mathrm{~mm}$ and length of $16 \mathrm{~mm}$ was revealed, which was located right after the origin of the left common carotid artery and extended to the descending thoracic aorta. There was a $58 \mathrm{mmHg}$ gradient across the narrowing. A decision was made to perform stenting of the entire obstructive segment using a Valeo stent that was $7.0 \mathrm{~mm}$ in diameter and $18 \mathrm{~mm}$ in length. Using a 0.014 " guidewire, the right coronary catheter (JR 3.5) was advanced into the ascending aorta. The guidewire was exchanged for an 0.035" Amplatzer super stiff guidewire with a 1-cm soft tip (Boston Scientific, Marlborough, MA, USA) to deliver the stent into the arch of the aorta so that it would completely cover the zone of obstruction. The correct location of the stent was monitored by injecting a contrast agent through the side arm of the delivery sheath. The stent was deployed at 10 atm. Repeat angiography demonstrated very good results with complete coverage of the narrowed segment (Figure 3B). There was no gradient between the ascending and descending aorta. The delivery catheter was removed from the aorta, and hemostasis was achieved. The chest tube was left in place, and the incision was closed.

There were no complications during the postoperative period. The child was extubated after $10 \mathrm{~h}$ and discharged home on postoperative day 7 in good condition and on no cardiac medications.

\section{Discussion}

Kutty et al. reported six cases of aortic arch stenting after initial surgical treatment of hypoplastic left heart syndrome with an average age of 5.6 months (0.5-12.9 months) and weight of $5.8 \mathrm{~kg}$ (2.9$7.7 \mathrm{~kg}$ ). Stents were implanted using the ascending aorta access approach [12] and required repeated dilatations depending on the child's growth at an average of 17.6 months (6.3-33.6) months after operation. Schmitz et al. performed stenting of the aortic arch in five pediatric patients with good clinical results; they also used the ascending aorta access approach and stated that stent implantation 

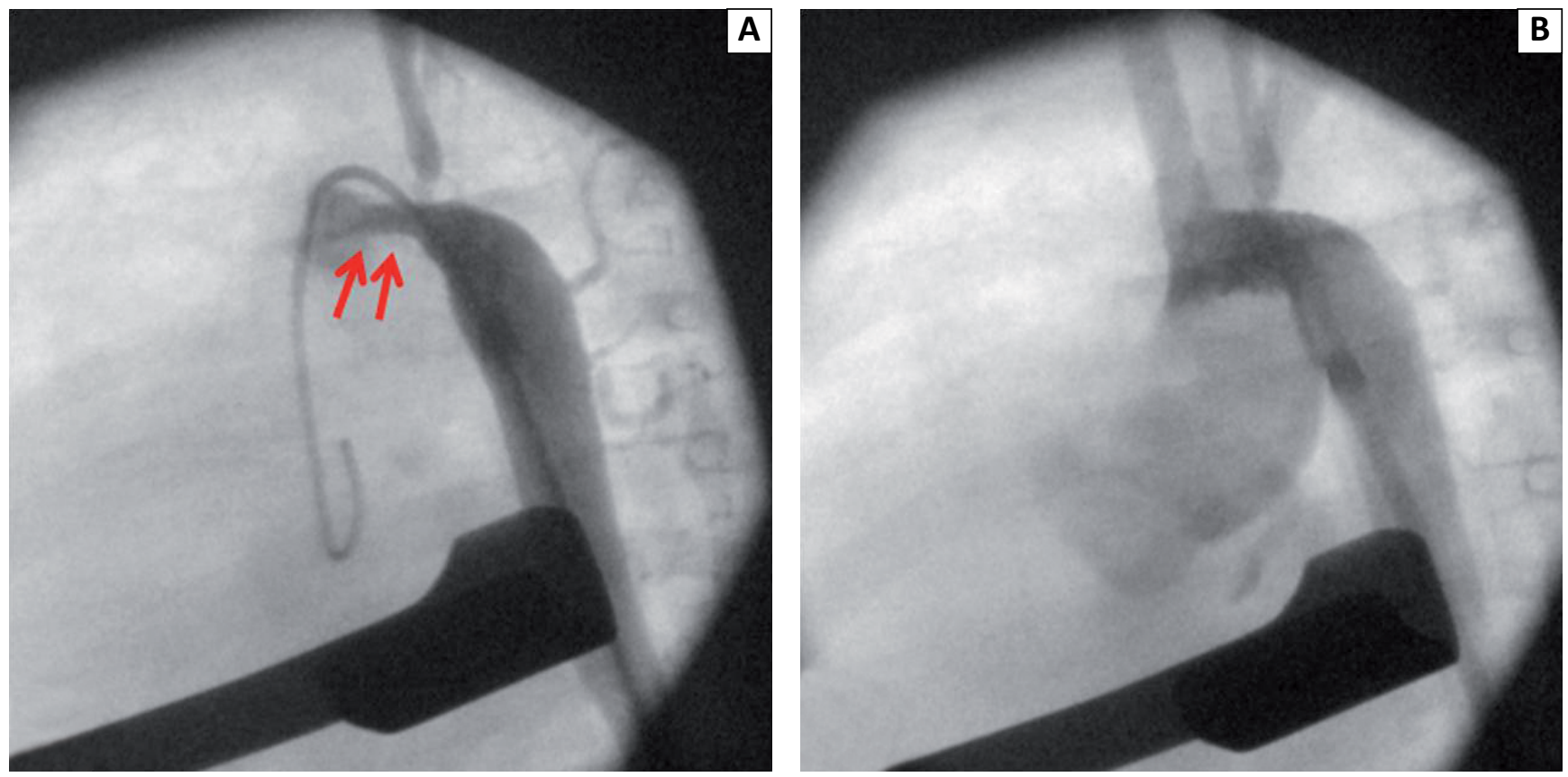

Figure 3. Patient aortography before (Panel A) and after (Panel B) stenting of the aortic arch and isthmus. Before stent implantation, there was severe stenosis of the aortic arch (arrow) and ostial stenosis of the left subclavial artery.

required repeated dilatation depending on the child's growth [13].

In our case, patient observation revealed a rapid development of aortic arch obstruction after initial correction of common arterial trunk and management of coarctation of the aorta. Performing PTA in this particular case was impractical due to the length of the obstructed segment, as PTA is often ineffective in patients with long stenosis and kinking or patients with hypoplastic distal aortic arch. Stent implantation is a more effective management strategy for this pathology, but stenting in infants and children is not always possible due to problems associated with delivering a stent suitable for future expansion as the patient grows. The use of stents that cannot be expanded to an adult size is not recommended and is only done in extreme emergencies $[14,15]$.

To overcome problems associated with the use of large-diameter delivery systems and balloon catheters as well as stents (e.g., GenezisXD, CP stent, Andrastents, Intrastent) with the potential for further re-dilatation to the size of an adult vessel, a hybrid stenting technique was proposed. These stents are manually mounted on a balloon catheter of the correct diameter and implanted without the use of long delivery devices $[12,13]$. Pediatric interventional cardiologists have recently started to use Valeo stents (Bard Peripheral Vascular, Inc., Tempe, AZ, USA) with a diameter of 6-10 $\mathrm{mm}$ for stenting large vessels. These stents are already mounted on the balloon catheter, have a low profile, require the use of 6-7-F introducers, and have the possibility of subsequent dilatation up to $20 \mathrm{~mm}$ in diameter [16]. In our case, we used a Valeo stent. In the future, we plan to monitor patient status and the gradient across the stent. As the child grows, if necessary, further balloon dilatation of the stent will be performed to achieve the required size.

For hybrid stenting of arch obstruction and aortic isthmus in our patient, we achieved access through the descending thoracic aorta. To our knowledge, this is the first report describing this technique in the literature. Positioning the patient on his or her side makes it possible to visualize the aortic arch without significant axial projections of the " $\mathrm{C}$-arm", which is important when performing an intervention in a standard cardiac surgical operating room. The use of lateral thoracotomy permits the avoidance of repeated sternotomy in patients without need for other cardiac interventions. Delivery of a 6-F system during implantation of Valeo stents through the thoracic descend- 
ing aorta is possible and safe. Thus, hybrid stenting of arch obstruction and aortic isthmus is possible via retrograde access through the descending thoracic aorta and produces good anatomical and hemodynamic results. The use of stents capable of further dilatation can achieve good long-term prognosis. Although one may argue that an iliac artery cut-down could have been used to deliver a 6-F introducer followed by stent delivery, we believe that our approach enabled us to deliver the stent safely without the need to reposition the child to best view the obstruction via angiography.

\section{Conflict of Interest}

The authors have no conflict of interest relevant to this publication.

\section{Comment on this Article or Ask a Question}

\section{References}

1. Januszewska K, Kozlik-Feldmann R, Kordon Z, Urschel S, Netz H, Reichart B, et al. Significance of the residual aortic obstruction in multistage repair of hypoplastic left heart syndrome. Eur J Cardiothorac Surg. 2011;40:508-13. DOI: 10.1016/j. ejcts.2010.12.023

2. Schaeffler R, Sarikouch S, Peuster M. Anterograde Stent Implantation for Treatment of Recurrent Coarctation After Norwood Operation. Pediatr Cardiol. 2008;29:388-392. DOI: 10.1007/s00246007-9130-y

3. Bockeria LA, Alekyan BG, Pursanov MG. Transluminal balloon angioplasty and stenting of coarctation and recoarctation of the aorta. In: Bockeria LA, Alekyan BG (eds). Practice of roentgenoendovascular surgery of the heart and vessels. Vol .2. Roentgenendovascular surgery of congenital and acquired heart diseases. Moscow: A.N. Bakulev Scientific Center of Cardiovascular Surgery RAMS; 2008:2015-36 (in Russ)

4. Rothman A, Galindo A, Evans WN, Collazos JC, Restrepo H. Effectiveness and safety of balloon dilation of native aortic coarctation in premature neonates weighing $<$ or $=$ 2,500 grams. Am J Cardiol. 2010;105:117680. DOI: 10.1016/j.amjcard.2009.12.023

5. Suarez de Lezo J, Pan M, Romero M. Percutaneous interventions on severe coarctation of the aorta: a 21-year experience. Pediatr Cardiol. 2005;26:176-189. DOI: 10.1007/s00246-004-0961-5

6. Vergales JE, Gangemi JJ, Rhueban KS, Lim DS. Coarctation of the Aorta - The Current State of Surgical and Transcatheter Ther- apies. Curr Cardiol Revs. 2013;9:211-219. DOI: 10.2174/1573403X113099990032

7. Ashcraft $T$, Jones $K$, Border W, Eghtesady $P$, Pearl JM, Khoury PR, et al. Factors affecting long-term risk of aortic arch recoarctation after the Norwood procedure. Ann Thorac Surg 2008; 85:1397-401. DOI: 10.1016/j. athoracsur.2007.11.054

8. Porras D, Brown D, Marshall A, del Nido P, Bacha E, McElhinney D. Factors associated with subsequent arch reintervention after initial balloon aortoplasty in patients with Norwood procedure and arch obstruction. J Am Coll Cardiol. 2011;58:868-76. DOI: 10.1016/j.jacc.2010.12.050

9. Haas NA, Happel CM, Blanz U, Laser KT, Kantzis M, Kececioglu D, et al. Intraoperative hybrid stenting of recurrent coarctation and arch hypoplasia with large stents in patients with univentricular hearts. Int J Cardiol. 2016;204:156-163. DOI: 10.1016/j. ijcard.2015.11.136

10. Venczelova Z, Tittel P, Masura J. First experience with andraStent $\mathrm{XL}$ implantation in children and adolescents with congenital heart diseases. Catheter Cardiovasc Interv. 2013;81:103-110. DOI: 10.1002/ccd.24505

11. Haas NA, Lewin MAG, Knirsch W, Nossal $\mathrm{R}$, Ocker V, Uhlemann F. Initial experience using the NuMED Cheatham Platinum (CP) stent for interventional treatment of coarctation of the aorta in children and adolescents. Z. Kardiol. 2005;94:113-120. 10.1007/s00392-005-0180-y

12. Kutty S, Burke RP, Hannan RL, Zahn EM. Hybrid aortic reconstruction for treatment of recurrent aortic obstruction after stage 1 single ventricle palliation: medium term outcomes and results of redilation, Catheter. Cardiovasc. Interv. 2011;78:93-100. DOI: https://doi.org/10.1002/ccd.22964

13. Schmitz C, Esmailzadeh B, Herberg U, Lang N, Sodian R, Kozlik-Feldmann R, et al. Hybrid procedures can reduce the risk of congenital cardiovascular surgery, Eur. J. Cardiothorac. Surg. 2008;34:718-725. 10.1016/j.ejcts.2008.06.028

14. Alekyan BG, Pursanov MG, Kim Al, Berishvilly DO, Grigoryan AM, Chuvarayan GA. Stenting of the coarctation of the aorta in critical newborns Statement of scientific center of cardiovascular surgery named after A.N. Bakulev. 2016. T. 17. № S3. C. 70a. (in Russ).

15. Cools B, Meyns B, Gewillig M. Hybrid stenting of aortic coarctation in very low birth weight premature infant. Catheter. Cardiovasc. Interv. 2013;81:195-198. DOI: $10.1002 /$ ccd. 24420

16. Kudumula V, Noonan P, Taliotis D, Duke C. Implantation and Preliminary Follow-Up of the Bard Valeo Stent in Pulmonary Artery Stenosis. Catheter Cardiovasc Interv. 2014;84;197-203. PMID: 24532385

Cite this article as: Pursanov MG, Svobodov AA, Levchenko EG, Atajanov UU. New Approach for Hybrid Stenting of the Aortic Arch in Low Weight Children. Structural Heart Disease. 2017;3(5):147-151. DOI: https://doi.org/10.12945/j.jshd.2017. 020.17 